\title{
Effect of warfarin on cell kinetics, epithelial morphology and tumour incidence in induced colorectal cancer in the rat
}

\author{
NICOLA GOETING, G A TROTTER, T COOKE, N KIRKHAM, AND I TAYLOR \\ From the University Surgical Unit, and Department of Pathology, Southampton General Hospital
}

SUMmaRY The effect of low dose warfarin and high dose warfarin on epithelial cell kinetics (as determined by stathmokinetic techniques), and preneoplastic morphological changes was studied during azoxymethane induced carcinogenesis in the rat. Warfarin, at either low or high dose, had no effect on crypt cell production rate (CCPR) at any time interval whereas tumour incidence in both low dose warfarin and high dose warfarin groups was significantly reduced. Morphological changes were observed using scanning electron microscopy, which by conventional histology were shown to be adenoma precursors. In the control group the number of microadenomas increased with time after starting azoxymethane. In warfarin treated animals, the number of microadenomas also increased with time, but the actual incidence was reduced when compared with controls. These results suggest that the effect of warfarin on tumour development is unrelated to its anticoagulant effect, because increased dose did not result in greater tumour reduction. Furthermore, there was no overall change in CCPR when warfarin was administered. Warfarin may exert a specific effect, by preventing neoplastic change in cells which have undergone morphologically undetectable functional changes associated with early carcinogenesis.

The adenoma carcinoma sequence has been shown in man, ${ }^{1}$ and more recently in animals. ${ }^{2}$ It is possible that anticoagulants may modify this sequence. Some anticoagulants are known to have an 'antimetastatic' effect in models where tumour cell lines have been injected, ${ }^{3}$ or where solid tumour has been implanted. ${ }^{4}$ In the latter type of experiment they have also been shown to reduce 'primary tumour' growth. More recent studies, on spontaneously metastasising autochthonous tumours, induced chemically, have shown similar effects. ${ }^{5}$ This finding is more relevant to the clinical situation.

A number of explanations for the mode of action of warfarin have been postulated. In particular, they have been said to act by a direct anticoagulant effect, ${ }^{6}$ or alternatively by a cytotoxic or cytostatic effect. $^{7}$

Previous studies have shown that the colonic mucosa of patients with colorectal cancer undergoes ultrastructural changes. ${ }^{8}$ These changes include crypt distortion, protrusion of epithelial cells, and

Address for correspondence: Miss N Goeting, University Surgical Unit. Centre Block, Southampton General Hospital, Southampton SO9 4XY. Received for publication 21 September 1984 breakdown of the mucous layer. Similar changes have been observed in the descending colon of rats treated with dimethylhydrazine. ${ }^{9}$ The incidence of induced tumours in the animal model used, is greatest in the distal colon and rectum, ${ }^{2}$ and this equates with the predominant distribution in man. For these reasons we have concentrated on changes in the descending colon and rectum.

To determine the mode of action of warfarin we have investigated its effect, at high and low dose, on cell kinetic parameters and epithelial morphology.

The kinetic studies should indicate whether a cytotoxic effect on cell proliferation is responsible for previously reported reductions in primary tumour incidence. ${ }^{5}$ If warfarin does not cause an overall change in the crypt cell production rate (CCPR), then it may have an effect on adenoma precursors which is detectable by scanning electron microscopy.

\section{Methods}

ANIMALS

One hundred and thirty male Cob Wistar rats 
received 12 weekly subcutaneous injection of azoxymethane, at a dose of $10 \mathrm{mg} / \mathrm{kg}$ week. At week eight they were divided into three groups: group 1 azoxymethane alone (control), $\mathrm{n}=50$; group 2 azoxymethane + low dose warfarin (LDW), $n=40$; group 3 - azoxymethane + high dose warfarin (HDW), $n=40$. Group 1 continued to receive azoxymethane alone. Groups 2 and 3 additionally received warfarin in their drinking water (LDW and HDW respectively). The intake of water was not monitored, but careful note was made of the clotting time (see below).

'Therapeutic' anticoagulation occurs when clotting times are between two and three times the mean normal clotting time. In the LDW group the warfarin dose was $0.6-1.2 \mathrm{mg} / \mathrm{l}$, and clotting times were in the range between normal and 'therapeutic' values. In the HDW group, 'therapeutic' anticoagulation was maintained, at a dose of between 1.2-1.8 $\mathrm{mg} / \mathrm{l}$. Clotting times were monitored using a thrombotest kit (Thrombotest, Nyegaard) on citrated venous blood taken from the tail vein (Fig. 1).

Ten animals were killed $10,15,20$, and 25 weeks after initial azoxymethane injection from each of the three groups, and in addition 10 animals were killed from the control group at five weeks. Ten normal animals, which had received neither azoxymethane nor warfarin were killed at time zero.

\section{STATHMOKINETIC STUDIES}

Animals were injected intraperitoneally with the vinca alkaloid, vincristine $(1 \mathrm{mg} / \mathrm{kg}$ ) (Lilly) which at this dose causes metaphase arrest. ${ }^{10}$ The number of arrested metaphases increases with time after injection. To prevent variation in kinetic results due to

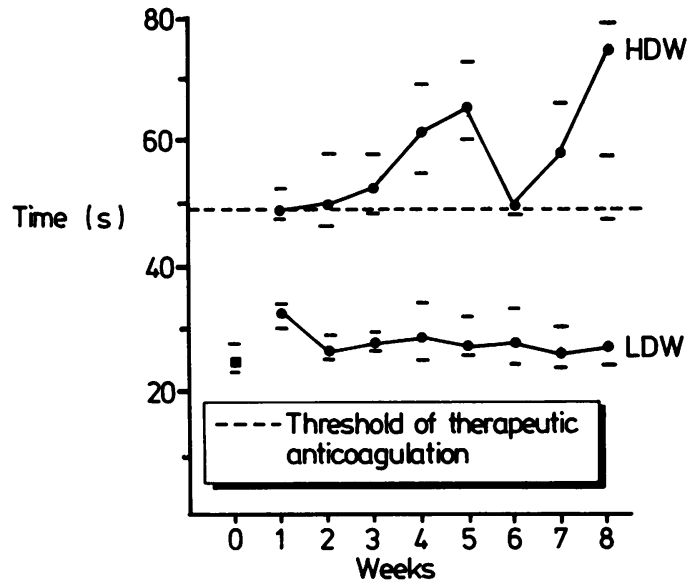

Fig. 1 Variation in clotting times during administration of low and high dose warfarin. diurnal changes, ${ }^{11}$ each procedure started at 9 am. In each group, the first animal was killed 30 minutes after injection with vincristine, and thereafter one animal was killed every 15 minutes up to $2 \frac{3}{4}$ hours. The colon was removed from each animal, opened, and washed in saline to remove faecal contents. Samples of approximately $1 \mathrm{~cm}^{2}$ were excised from caecum, ascending colon, transverse colon, descending colon, and rectum. They were fixed in Carnoy's solution for four to six hours, and then transferred to $70 \%$ alcohol for storage.

Subsequently specimens were rehydrated on an alcohol gradient, and hydrolysed tissue was stained with periodic acid Schiff's reagent as part of the Feulgen reaction. Crypts were microdissected in $15 \%$ acetic acid, and a wet squash preparation of each sample made for microscopic examination (Fig. 2).

Each group of animals killed, at each time interval, generated 50 samples - that is, 10 animals, five areas. The number of arrested metaphases was counted in 10 crypts for each sample, and the mean metaphase count plotted against the time that the sample was taken (10 points, $\left.30 \mathrm{~min}-2 \frac{3}{\mathrm{~h}} \mathrm{~h}\right)$. The crypt cell production rate (CCPR) - that is, the mean number of cells produced per crypt per hour was calculated for each site, in each group, from the slope of the graph (Fig. 3).

In those animals killed at 25 weeks, tumour incidence, distribution, and volume were also noted in each colon before excision of samples for cell kinetic studies.

\section{SCANNING ELECTRON MICROSCOPY}

After sampling for CCPR, samples of descending colon and rectum were taken from 28 animals for scanning electron microscopy. These included two normal, 10 control (two each at 5, 10, 15, 20, and 25 weeks), eight LDW and eight HDW (two each at 10, 15,20 , and 25 weeks).

Samples measuring approximately $1 \mathrm{~cm}^{2}$ were excised and pinned flat in $10 \%$ formol saline. They were then postfixed in osmium tetroxide for two hours. Subsequently they were washed in distilled water, then dehydrated on an acetone gradient and subjected to critical point drying with liquid carbon dioxide. Samples were mounted on aluminium stubs, sputter coated with gold and palladium, then scanned using the JEOL 35 scanning electron microscope. Micrographs were taken at $\times 40$ magnification and the following parameters were determined: (1) the number of microadenomas per low power field; (2) the area of each microadenoma (using the Apple II graphics tablet); (3) the number of crypts per microadenoma.

For the purposes of this study no distinction was 


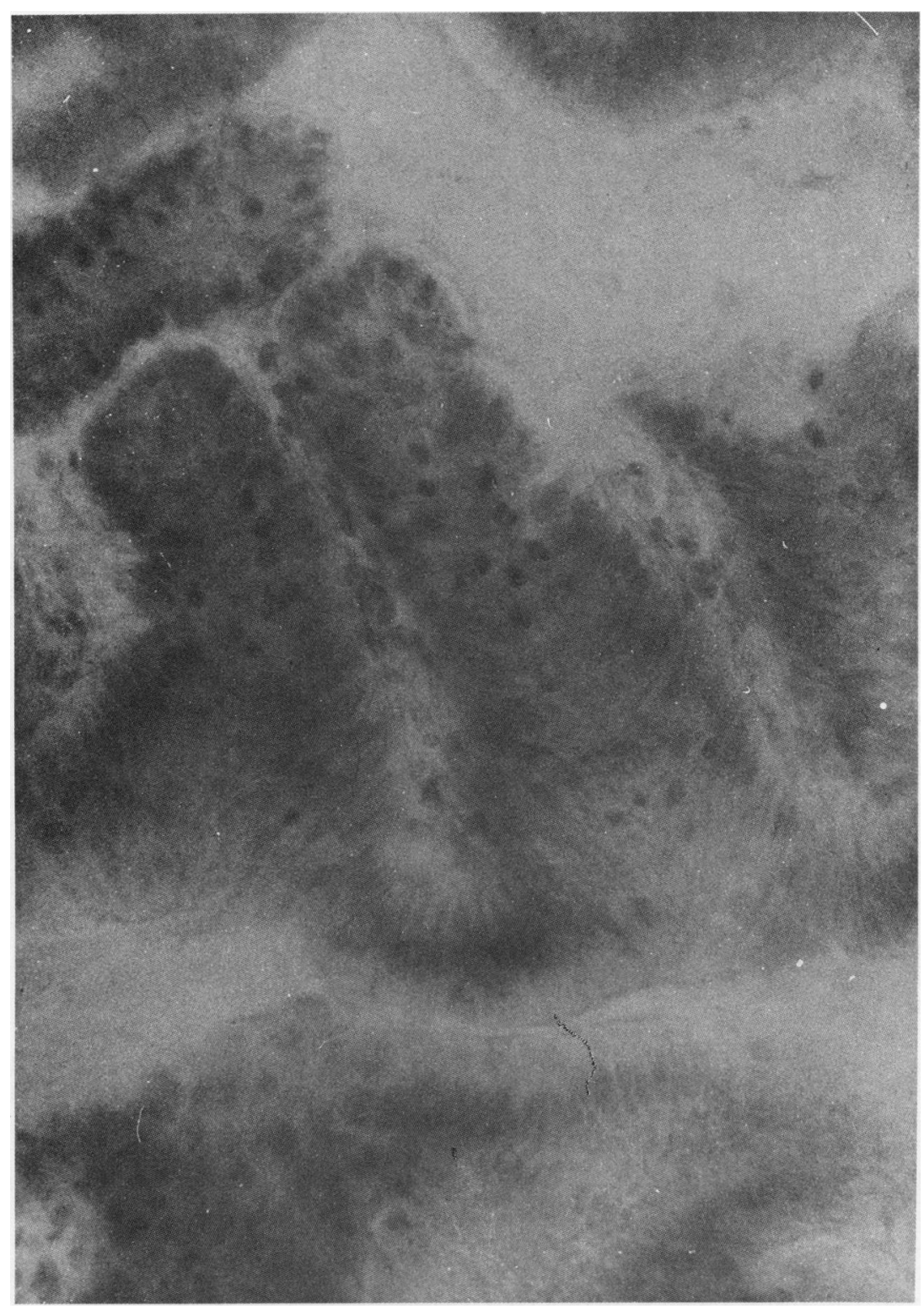

Fig. 2 Crypt microdissection/squash preparation, stained with Periodic acid Schiff showing metaphase arrest $(\times 150$ original magnification $)$.

made between distal colon and rectum, as results from an earlier study ${ }^{2}$ have shown that morphological epithelial changes during carcinogenesis are similar in both areas.

STATISTICAL ANALYSIS

In the calculation of CCPR, linear regression analysis was carried out to determine the correlation coefficient. The standard deviations of the slopes were also calculated but, as is normal practice in this analysis, they were not quoted. Cell kinetic data between the different groups were compared for statistical significance using Student's $t$ test, modified for this model. ${ }^{12}$ 


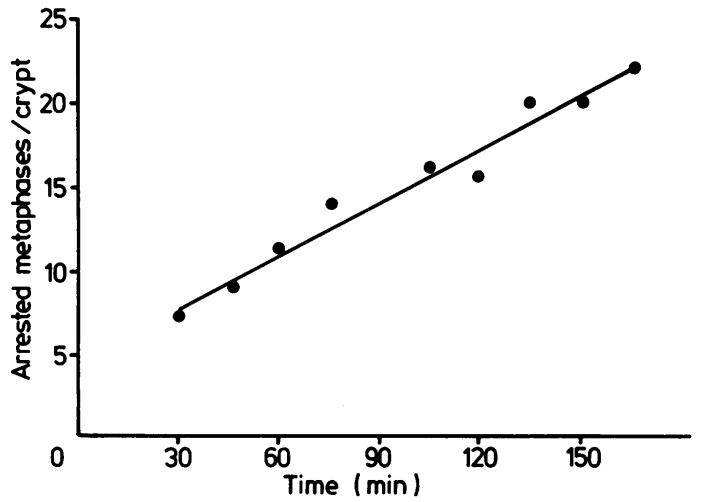

Fig. 3 Linear relationship of metaphase arrest to time, used to calculate CCPR.

All other statistical analyses were done using the Mann Whitney U test for non-parametric variables.

\section{Results}

\section{CLOTTING TIME}

As indicated in Figure 1, clotting times determined by the thrombotest method were as follows: in normal animals the median clotting time was 24.7 seconds (range 23.6-29.6), in animals receiving HDW the clotting times were greater than 49.4 seconds - that is, therapeutic levels, and in animals receiving LDW they were between 24.7 and 49.4 seconds - that is, 'non-therapeutic' levels. Clotting times within each of the two groups - that is, LDW and HDW, were equivalent.

\section{CELL KINETICS}

Linear regression analysis of metaphase arrest graphs gave a correlation coefficient of 0.98 or greater in all cases. In normal animals, variations in CCPR along the colon were observed (time interval 0 , Table 1). The highest values were seen in the caecum $(10 \cdot 23)$, with intermediate values in the ascending colon and descending colon (7.96 and 6.36 respectively). The lowest values were observed

Table 1 Crypt cell production rate at sites sampled during induction of carcinogenesis in normal animals

\begin{tabular}{|c|c|c|c|c|c|}
\hline $\begin{array}{l}\text { Time } \\
(w k s)\end{array}$ & Caecum & $A C$ & $T C$ & $D C$ & Rectum \\
\hline 0 & $10 \cdot 23$ & $5 \cdot 48$ & $7 \cdot 96$ & $5 \cdot 60$ & $6 \cdot 36$ \\
\hline 5 & $10 \cdot 20$ & 6.40 & $8 \cdot 80$ & 6.93 & $6 \cdot 84$ \\
\hline 10 & $10 \cdot 40$ & $6 \cdot 55$ & 8.96 & $5 \cdot 11$ & $7 \cdot 56$ \\
\hline 15 & 11.04 & $8 \cdot 21$ & $9 \cdot 20$ & $7 \cdot 80$ & $9 \cdot 01$ \\
\hline 20 & 12.07 & $8 \cdot 16$ & $10 \cdot 90$ & 9.93 & $11 \cdot 30$ \\
\hline 25 & $13 \cdot 33$ & $10 \cdot 34$ & $12 \cdot 40$ & $11 \cdot 13$ & 12.01 \\
\hline
\end{tabular}

in the transverse colon and rectum (5.48 and 5.6). There were significant differences between some, but not all, sites. ${ }^{2}$

\section{Control study}

In the control group - that is, non-warfarin treated animals, CCPR increased with time after initiation of carcinogenesis. This increase was highly significant between five and 25 weeks $(p<0.01)$, and significant between 20 and 25 weeks $(p<0.05)$. The percentage increase in CCPR was greatest in the rectum $(88.8 \%)$ where the value for CCPR was initially low and the final tumour incidence was highest; and least in the caecum $(30.3 \%)$, where CCPR was initially highest (Table 1) and the final tumour incidence was lowest.

\section{Warfarin groups}

In the LDW and HDW groups, CCPR also increased with time after initial azoxymethane administration. The CCPR values obtained for both LDW and HDW groups were, however, not significantly different from controls at any time interval. That is, the values for CCPR in LDW and HDW groups at any site, either caecum, ascending colon, transverse colon, descending colon, or rectum, at any time interval studied, either $10,15,20$, or 25 weeks, were not significantly different from the corresponding values in the control group. For example, in the rectum at 10 weeks, the control CCPR was $7 \cdot 56$, LDW was 7.24 and HDW was 7.73. At 25 weeks, values were as follows: control 12.01, LDW 12.66, and HDW 11.86 (Table 2).

\section{TUMOUR VOLUME AND INCIDENCE}

In those animals killed at 25 weeks, the number of malignant tumours was significantly reduced in both LDW and HDW groups when compared with controls (17 in each group of warfarin treated animals, and 37 in controls, $p<0.05$, see Table 3 ).

Table 2 Crypt cell production rate during induction of carcinogenesis in warfarin treated animals

\begin{tabular}{|c|c|c|c|c|c|}
\hline $\begin{array}{l}\text { Time } \\
(w k s)\end{array}$ & Caecum & $A C$ & $T C$ & $D C$ & Rectum \\
\hline \multicolumn{6}{|c|}{ Low dose warfarin } \\
\hline 10 & $9 \cdot 60$ & $9 \cdot 66$ & $10 \cdot 26$ & $3 \cdot 60$ & $7 \cdot 24$ \\
\hline 15 & $16 \cdot 62$ & $10 \cdot 44$ & $11 \cdot 22$ & $9 \cdot 24$ & $8 \cdot 46$ \\
\hline 20 & $10 \cdot 20$ & $13 \cdot 08$ & $14 \cdot 70$ & $12 \cdot 24$ & $9 \cdot 48$ \\
\hline 25 & $17 \cdot 82$ & $11 \cdot 58$ & $7 \cdot 74$ & $12 \cdot 54$ & $12 \cdot 66$ \\
\hline \multicolumn{6}{|c|}{ High dose warfarin } \\
\hline 10 & $11 \cdot 33$ & $5 \cdot 98$ & $8 \cdot 58$ & $5 \cdot 49$ & $7 \cdot 73$ \\
\hline 15 & $11 \cdot 79$ & $7 \cdot 59$ & $9 \cdot 10$ & 6.93 & $8 \cdot 95$ \\
\hline 20 & $12 \cdot 86$ & $9 \cdot 24$ & $11 \cdot 25$ & $10 \cdot 25$ & $10 \cdot 70$ \\
\hline 25 & $14 \cdot 23$ & $10 \cdot 71$ & $12 \cdot 81$ & $11 \cdot 91$ & $11 \cdot 86$ \\
\hline
\end{tabular}


Table 3 Tumour incidence and tumour volume in control, low dose warfarin (LDW) and high dose warfarin (HDW) groups

\begin{tabular}{llll}
\hline & & \multicolumn{2}{l}{ Median tumour } \\
\cline { 3 - 4 } Group & $\begin{array}{l}\text { Tumour } \\
\text { (no) }\end{array}$ & Incidence (range) & $V^{\prime} / \mathrm{mm}^{3}$ (range) \\
\hline Control & 37 & $3 \cdot 0(2-8)$ & $840(264-3126)$ \\
LDW & $17^{*}$ & $2 \cdot 0(0-3)^{*}$ & $560(56-1250)$ \\
HDW & $17 \dagger$ & $2 \cdot 0(0-5)^{\dagger}$ & $1001(114-3113)$ \\
\hline
\end{tabular}

${ }^{*} p<0 \cdot 05 . \quad+p<0 \cdot 01$. NS

Median tumour incidence is quoted since the distribution is skewed. Tumour burden (total tumour volume per animal $/ \mathrm{mm}^{3}$ ) in warfarin treated animals was not significantly different from that in controls. Tumour incidence was greatest in the descending colon and rectum, followed by the transverse colon, the ascending colon and the caecum respectively.

\section{MORPHOLOGICAL CHANGES}

In the distal colon and rectum, at low magnification, the mucosa was relatively flat, and crypt orifices had a round, regular appearance (Fig. 4a). In contrast the ultrastructural appearance changed with time after initiation of carcinogenesis. There was loss of crypt regularity, with marked slit like distortion or crypt orifices (Fig. 4b).

\section{Microadenoma formation}

In the control group, after only five weeks azoxymethane treatment, small raised areas were observed, encompassing one to three crypts (Fig. 5). Scanning electron microscopy samples were reprocessed and sections through the lesions submitted for conventional histology. This showed epithelial dysplasia in the upper portion of the crypt, which at a later stage of treatment with azoxymethane extended to a greater depth (Fig. 6). Widening and branching of crypts also occurred. These morphological changes were similar to the dysplastic changes observed in histological sections of adenomas from the same model; therefore the lesions were termed microadenomas. ${ }^{2}$ The mean number of microadenomas per low power field, mean area, and mean number of crypts per microadenoma were then determined in samples from the distal colon and rectum in all groups, at each time interval.

\section{Number of microadenomas}

In the control group the median number of microadenomas increased with time after initial injection. This increase was highly significant between five weeks (median 3.5, range 3-4), and 25 weeks (median $14 \cdot 0$, range $4-22, \mathrm{p}<0 \cdot 01$ ). A significant difference was also found between 20 weeks (median 9.0, range 3-15) and 25 weeks $(\mathrm{p}<0 \cdot 05)$. In the LDW and HDW groups, microadenomas were also observed, and similarly the number increased with time. The numbers of microadenomas in both LDW and HDW groups were significantly lower than in control animals, at all time intervals $(\mathrm{p}<0.01$ in most cases, see Table 4). At 10 weeks - that is, after only two weeks of warfarin treatment - the number of microadenomas in the HDW group was significantly lower than in the LDW group ( $p=0 \cdot 0214)$. From 15 weeks onwards there was no difference in the number of microadenomas between the two warfarin groups.

\section{Area of microadenomas}

The mean area of microadenomas was not significantly different between controls, and LDW and HDW groups at any time interval (Table 5). There was, however, a gradual increase in area with time in each of the groups.

\section{Mean number of crypts per microadenoma}

The mean number of crypts per microadenoma in controls, LDW and HDW groups were also not significantly different at any time interval (Table 6).

\section{Discussion}

In a previous study we showed that a relationship existed between morphological appearance of normal epithelium and normal crypt cell kinetics. ${ }^{2}$ This confirmed that normal function is intricately related to structure. We also reported that structural changes, seen during carcinogenesis were associated with altered cell proliferation. These changes may therefore be a consequence of functional change.

In this study, our aim was to determine whether previously reported reductions in tumour incidence with warfarin administration ${ }^{6}$ are the result of an overall effect on cell proliferation; or of a specific

Table 4 Incidence of microadenomas in control and warfarin treated animals at various time intervals, in the distal colon

\begin{tabular}{llll}
\hline \multirow{2}{*}{$\begin{array}{l}\text { Time } \\
(w k s)\end{array}$} & \multicolumn{3}{l}{ Median microadenoma-incidence (range) } \\
\cline { 2 - 4 } & Control & LDW & $H D W$ \\
\hline 5 & $3 \cdot 5(3-4)$ & - & - \\
10 & $7 \cdot 5(0-12)$ & $1 \cdot 0(0-6)^{*}$ & $0(0-1)$ \\
15 & $7 \cdot 0(3-15)$ & $0(0-3)$ & $1(0-3)$ \\
20 & $9 \cdot 0(3-15)$ & $0 \cdot 5(0-3)$ & $1(0-5)$ \\
25 & $14 \cdot 0(4-22)$ & $0(0-5)$ & $0(0-3)$ \\
\hline
\end{tabular}

${ }^{*} \mathrm{p}<0 \cdot 02 . \quad \mathrm{p}<0 \cdot 01$ (all other control/warfarin comparisons) 

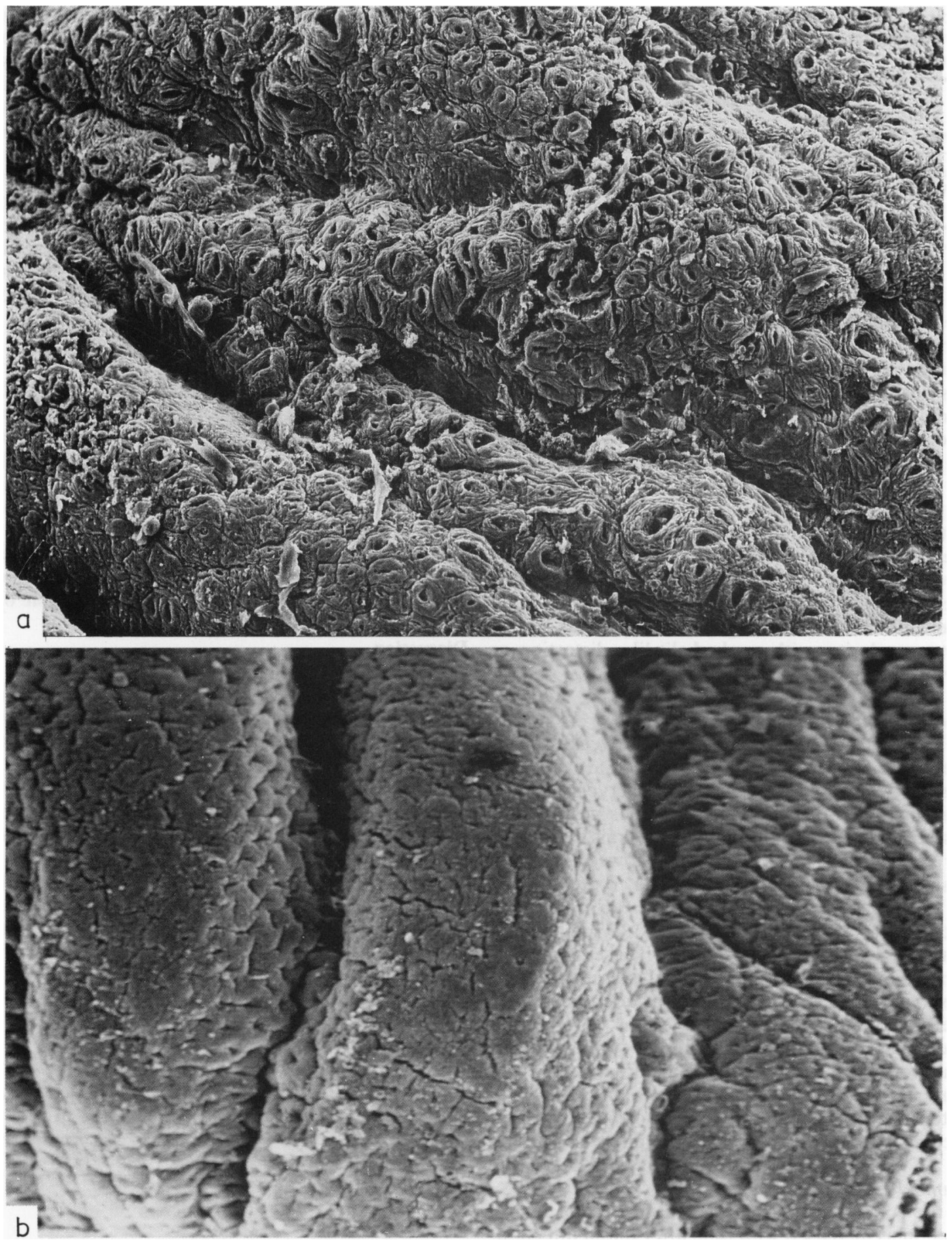

Fig. 4 Scanning electron micrographs of distal colon: (a) Normal epithelium characterised by smooth surface appearance and regularity of crypts $(\times 40$ original magnification); (b) Dysplastic epithelium following 20 weeks azoxymethane treatment. Surface irregularity and marked crypt distortion due to protrusion of cells $(\times 40$ original magnification $)$. 


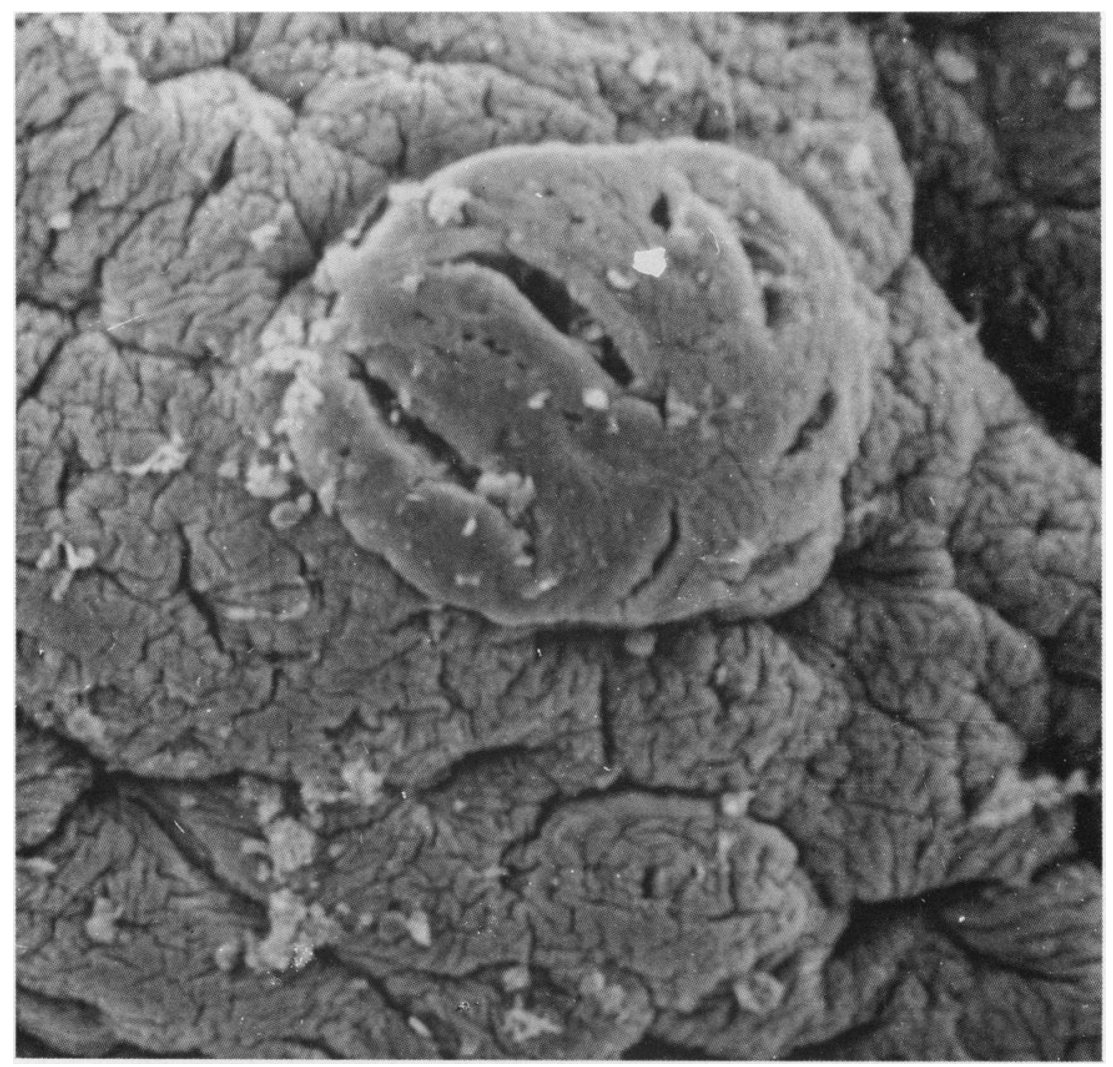

Fig. 5 Scanning electron micrograph of distal colon (five weeks treatment with azoxymethane) showing the presence of a microadenoma $(\times 40$ original magnification).

target effect on the adenoma carcinoma sequence, either at the stage of malingnant transformation, or even earlier. To ascertain whether the action of warfarin was directly related to its anticoagulant properties, warfarin was administered at 'therapeutic' and 'non-therapeutic. levels.

The results obtained in this study confirm that

Table 5 Area of microadenomas in control and warfarin treated animals at various time intervals, in the distal colon

\begin{tabular}{llll}
\hline \multicolumn{5}{c}{$\begin{array}{l}\text { Median microadenoma area } \\
\text { Time } \\
(w k s)\end{array}$} & Control & LDW & HDW \\
\cline { 2 - 4 } & magnification factor) (range) & \\
\hline 5 & $33 \cdot 0(16-70)$ & - & - \\
10 & $37 \cdot 5(9-91)$ & $44 \cdot 5(7-108)$ & $42 \cdot 5(12-91)$ \\
15 & $50 \cdot 0(18-137)$ & $47 \cdot 0(33-106)$ & $49 \cdot 0(18-106)$ \\
20 & $67 \cdot 0(40-137)$ & $69 \cdot 0(27-167)$ & $60 \cdot 0(15-192)$ \\
25 & $98 \cdot 0(30-223)$ & $86 \cdot 0(34-145)$ & $85 \cdot 0(55-147)$ \\
& NS & & \\
\hline
\end{tabular}

warfarin has no field effect on colonic epithelial proliferation, although a reduction in tumour number was seen. This reduction observed at both low and high dose, supports the hypothesis that warfarin exerts a cytotoxic effect. as suggested by Lisnell, ${ }^{7}$ rather than an anticoagulation effect. This postulated cytotoxic effect however was not detectable

Table 6 Number of crypts per microadenoma in control and warfarin treated animals at various time intervals, in the distal colon

\begin{tabular}{llll}
\hline \multirow{2}{*}{$\begin{array}{l}\text { Time } \\
(w k s)\end{array}$} & \multicolumn{3}{l}{ Median number of crypts per microadenoma (range) } \\
\cline { 2 - 4 } & Control & LDW & $H D W$ \\
\hline 5 & $2 \cdot 0(2-5)$ & - & - \\
10 & $3 \cdot 0(2-6)$ & $2 \cdot 0(2-6)$ & $2 \cdot 5(2-4)$ \\
15 & $2 \cdot 0(2-4)$ & $2 \cdot 0(2-4)$ & $2 \cdot 0(2-5)$ \\
20 & $3 \cdot 0(2-6)$ & $2 \cdot 0(2-6)$ & $3 \cdot 0(2-7)$ \\
25 & $3 \cdot 0(2-7)$ & $2 \cdot 0(2-10)$ & $3 \cdot 0(2-8)$ \\
& NS & & \\
\hline
\end{tabular}




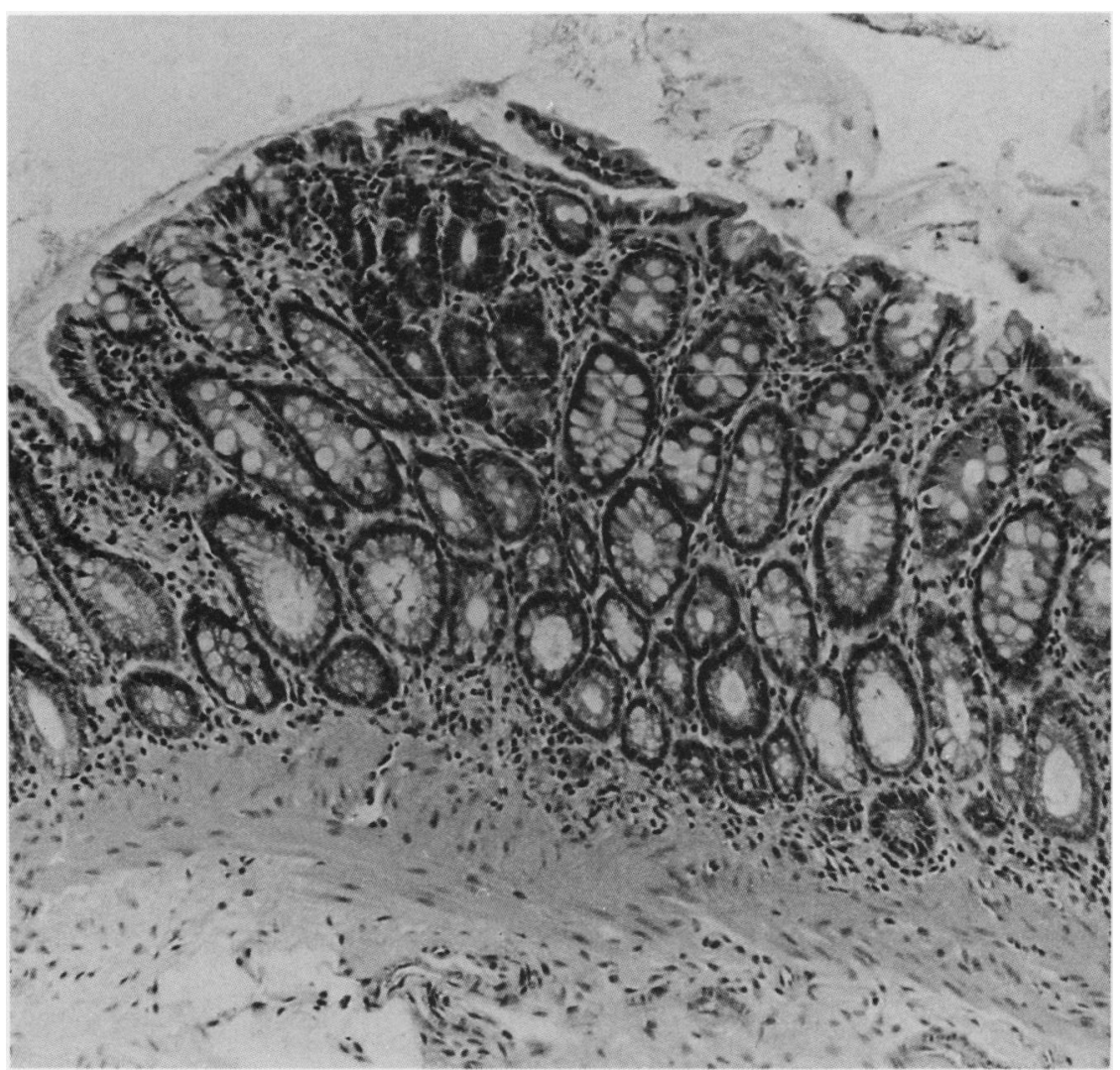

Fig. 6 Histological features of a microadenoma demonstrating epithelial dysplasia. (Haematoxylin and eosin $\times 250$ original magnification).

by the cell kinetic techniques we used because stathmokinetic techniques quantify whole crypt changes, rather than changes in individual cells within the crypts.

As warfarin does not cause a field change in cell kinetic parameters, it must be concluded that there is a specific target effect at some stage during the adenoma carcinoma sequence. Lamont and O'Gor$\operatorname{man}^{13}$ have shown that 5,6 ,dihydroxytryptamine, when administered to rats with dimethylhydrazine induced tumours, caused specific tumour necrosis, while normal epithelium in the same animals was unaffected. In our study, warfarin was administered before the formation of frank tumours, and accordingly it must exert a similar target effect on the adenoma carcinoma sequence, either at or prior to malignant transformation.

If warfarin acts by preventing malignant transformation, then the number of microadenomas should be the same in both control and warfarin treated animals. In contrast, however, if warfarin acts before malignant transformation the number of microadenomas should be reduced in warfarin treated animals when compared with controls.

In our study we observed that the latter was the case - that is, the number of microadenomas was decreased. This indicates that warfarin does indeed act at a pre-adenomatous stage. We suggest therefore that warfarin is acting specifically on cells which have undergone functional changes associated with preneoplasia, but which are not morphologically different from normal epithelial cells. This functional change may predispose to increased susceptibility to the action of warfarin, even at low dose, although some cells, which are not inhibited by warfarin, subsequently develop into microadenomas and frank tumours, as in controls. This hypothesis is supported by the observation that there is no difference in the tumour volumes observed in the different groups of animals studied.

In summary we have reached the following conclusions: (1) warfarin does not exert an overall 
effect on colonic epithelial cell kinetics, therefore it acts on specific cells. This is not demonstrable by the stathmokinetic techniques which we used; (2) the action of warfarin is independent of the degree of anticoagulation because the tumour incidence is equally reduced in both high and low dose warfarin groups; (3) when microadenomas arise during warfarin administration, the area of the lesions is unaffected when compared with that of controls. Therefore if premalignant cells are refractory to the effect of warfarin, their subsequent growth is unaffected; (4) as microadenoma formation is reduced in animals treated with warfarin, it acts prior to this stage of carcinogenesis.

Further studies are required to determine the mechanism by which warfarin acts on susceptible cells at this very early stage of carcinogenesis.

We gratefully acknowledge the Wessex Medical School Trust, who awarded a grant to enable these studies to be carried out. We also wish to thank the Department of Electron Microscopy, in particular Mr C Inman, for their help in this study, and Professor N Wright, of the Royal Postgraduate Medical School, who instructed us in the stathmokinetic techniques.

\section{References}

1 Morson BC, Dawson IMP. The polyp cancer sequence. In: Gastrointestinal pathology. Oxford: Blackwell Scientific Publications, 1972: 542-51.

2 Cooke T, Kirkham N, Stainthorp DH, Inman C, Goeting N. The detection of early neoplastic changes in experimentally induced colorectal cancer, using scanning electron microscopy and cell kinetic studies. Gut 1984; 25: 748-55.

3 Orme S, Ketcham AS. The effect of prolonged anticoagulation on spontaneous metastases. Surg Forum 1967; 18: 84-5.

4 Ryan JJ, Ketcham AS, Wexler H. Warfarin treatment of mice bearing autochthonous tumours: effect on spontaneous metastases. Science 1968; 162: 1493.

5 Mooney B, Serlin M, Taylor I. The effect of warfarin on spontaneously metastasising colorectal cancer in the rat. Clin Oncol 1982; 8: 55-9.

6 Brown JM. A study of the mechanism by which anticoagulation with warfarin inhibits blood borne metastases. Cancer Res 1973; 33: 1217-24.

7 Lisnell A, Mellgren J. Effect of heparin, protamine, dicoumarol, streptokinase and epsilon-amino-Ncaproic acid on the growth of human cells in vitro. Acta Pathol Microbiol Scand 1963; 57: 145-53.

8 Traynor OJ, Costa NL, Blumgart LH, Wood CB. A scanning electron microscopy study of ultrastructural changes in the colonic mucosa of patients with large bowel tumours. Br J Surg 1981; 68: 701-4.

9 Barkla DH, Tutton PJM. Surface changes in the descending colon of rats treated with dimethylhydrazine. Cancer Res 1977; 37: 262-71.

10 Wright NA, Appleton DR. The metaphase arrest technique. A critical review. Cell Tissue Kinet 1980; 13: 643-63.

11 Deschner Eleanor E, Lipkin M. Proliferation and differentiation of gastrointestinal cells. In: Lipkin M, Good RA, eds. Gastrointestinal tract cancer. Sloane Kettering Institute Cancer Series, New York, London: Plenum Medical Book Company 1978: 14.

12 Aherne WA, Camplejohn RS, Wright NA. How to analyse the cell cycle: I. In: An introduction to cell population kinetics. London: Edward Arnold, 1977: 24.

13 Lamont JT, O'Gorman TA. Experimental colonic cancer. Gastroenterology 1978; 75: 1157-69. 
the same fashion in response to different opioid medications? Unfortunately, I and my colleagues were unable to convince reviewers of other journals of that important fact. Perhaps our observations, belatedly conveyed here in the form of a letter, will lend support to the careful study of Dowlatshahi $e t$ al. I wonder how many other research drawers contain 'dead' yet viable data?

GI Unit, S N SULLIVAN

Victoria Hospital, London N6A 4G5, Ontario, Canada.

\section{Books}

Precancerous lesions of the gastrointestinal tract. Edited by B C Mason and J R Jass. (Pp. 174; illustrated; £22.50.) London: Bailliere Tindal, 1985. Pathologists are often amused when, having presented a paper, they are congratulated on the beautiful pictures with the scientific content forgotten. I am in danger of doing the same with this book. The colour photomicrographs are of the highest standard and the transparencies, which can be bought separately, will be even better. If pathology is not to be regarded as simply pattern recognition, the text of an atlas is important. In a short space the essential points are covered but perhaps in the interest of brevity, misleading and inaccurate statements have crept in. The difficult subjects of severe dysplasia, in situ and intramucosal carcinoma are not well tackled. In the gastric section we are told that a distinction between severe dysplasia and intramucosal carcinoma has important treatment implications yet it appears that severe dysplasia amounting to in situ carcinoma is almost always associated with invasive carcinoma. Again in the colorectal area severe dysplasia without invasion of the muscularis mucosa is regarded as in situ carcinoma when any form of invasion eliminates an in situ lesion. It is stated that no lymphatics are present in the colorectal mucosa when they are known to occur around the crypts. These cannot be regarded as major faults and may help in an important function the promotion of discussion.

When another edition is contemplated a section on cytology would indicate the value of correlating cytological and histological appearances. This book will be useful to pathologists and clinicians and is good value.

D J POLLOCK

\section{News}

\section{Third European Symposium on Gastrointestinal Motility}

This meeting will be held from 16-18 June 1986. Closing date for abstracts is 8 March 1986. Further details from Prof $G$ Vantrappen, University Hospital, St Rafael-Gathuisberg, Herestraat 49, 3000 Leuven, Belgium.

\section{Emergency in Gastroenterology}

A symposium dealing with recent developments in this field will be held from 30 April to 2 May 1986 at Klinikum rechts der Isar, Munich, FRG. Details from PD Dr med G E Vogel, Ismaningerstrasse 22, D-8000 Munich 80, FRG.

\section{FASEB Summer Research Conference}

To be held from 20-25 July 1986 in Vail, Colorado, USA, on physiology and pathology of the splanchnic circulations. Details from the FASEB, Splanchnic Circulation Conference, 9650 Rockville Pike, Bethesda, Maryland 20814, USA.

\section{Corrections}

\section{Correction}

In line 6 of the BSG abstract on toddler diarrhoea by Guerro, Brown and McNeish (Gut, October 1985, T.22) the words 'mouth to caecum transit' should read 'mouth to anus transit'.

\section{Correction}

In the paper entitled 'Effect of warfarin on cell kinetics . . . (Gut 1985; 26: 807-15) Figures a and b on p. 812 have been reversed in error.

In the leading article by J B Elder (Gut December 1985) p. 1280 , second paragraph, line two should read ' $(2000 \mathrm{mg} / \mathrm{kg} /$ day $)$ lasting from 875-903 days with plasma blood concentrations . . .' 